\title{
O ensino remoto emergencial: ações e adaptações de estudantes cearenses
}

\author{
Emergency remote education: actions and adaptations of students from Ceará \\ Enseñanza remota de emergencia: acciones y adaptaciones de estudiantes de Ceará
}

Recebido: 21/12/2021 | Revisado: 28/12/2021 | Aceito: 03/01/2022 | Publicado: 04/01/2022

Nairley Cardoso Sá Firmino
ORCID: https://orcid.org/0000-0002-7684-5371
Universidade da Integração Internacional da Lusofonia Afro-Brasileira, Brasil
E-mail: nairleysafirmino@gmail.com
Diego Farias Firmino
ORCID: https://orcid.org/0000-0003-3921-2089
Secretaria de Educação do Ceará, Brasil
E-mail: diego.firmino.ced@prof.ce.gov.br
Elton Patrick Barbano
ORCID: https://orcid.org/0000-0003-2726-6573
Universidade Estadual Vale do Acaraú, Brasil
E-mail: barbanotrick@gmail.com
Glaydson Leandro Farias Mendonça
ORCID: https://orcid.org/0000-0002-3773-5778
Universidade Estadual Vale do Acaraú, Brasil
E-mail: leandromend@yahoo.com.br
Luciana Rodrigues Leite
ORCID: https://orcid.org/0000-0003-1915-6462
Universidade Estadual Vale do Acaraú, Brasil
E-mail: lurodleite@gmail.com

\section{Resumo}

A Covid-19 impactou a educação, destarte, esta pesquisa objetivou compreender como os estudantes cearenses vivenciaram os estudos domiciliares, por meio ou não do Ensino Remoto Emergencial (ERE). O estudo de caso com abordagem quali-quantitativa foi realizado por meio de questionários respondidos por 1317 estudantes. $\mathrm{O}$ cálculo do ranking médio e a análise de conteúdo foram utilizados na análise de dados. Os estudantes consideraram a aprendizagem abaixo da média e expressaram interesse no uso parcial das interfaces digitais. A ansiedade e a dispersão foram associadas às dificuldades na aprendizagem; e o retorno às atividades presenciais provocava receios. Conclui-se que o ERE, apesar das controvérsias, contribuiu com a aprendizagem na pandemia.

Palavras-chave: Estudos domiciliares; Aprendizagem; Estudantes cearenses; Pandemia.

\begin{abstract}
Covid-19 had an impact on education, so this research aimed to understand how students from Ceará experienced home studies, through or without Emergency Remote Education (ERE). The case study, with a qualitative and quantitative approach, was carried out with questionnaires, answered by 1317 students. The calculation of the average ranking and content analysis were used in the data. Students consider learning below average and expressed interest in the partial use of digital interfaces. Anxiety and dispersion were associated with learning difficulties and the return to face-to-face activities still causes fears. It is concluded that the ERE, despite the controversies, contributed to the learning in the pandemic.
\end{abstract}

Keywords: Home studies; Learning; Students from Ceará; Pandemic.

\section{Resumen}

Covid-19 tuvo un impacto en la educación, por lo que esta investigación tuvo como objetivo comprender cómo los estudiantes de Ceará experimentaron los estudios en el hogar, a través o no a través de Educación Remota de Emergencia (ERE). El estudio de caso con enfoque cuali-cuantitativo se realizó a través de cuestionarios respondidos por 1317 estudiantes. En los datos se utilizó el cálculo de la clasificación promedio y el análisis de contenido. Los estudiantes consideraron el aprendizaje por debajo del promedio y expresaron interés en el uso parcial de interfaces digitales. La ansiedad y la dispersión se asociaron con dificultades de aprendizaje; y el regreso a las actividades presenciales aún genera temores. Se concluye que el ERE, a pesar de las controversias, contribuyó al aprendizaje en la pandemia.

Palabras clave: Estudios en el hogar; Aprendiendo; Estudiantes en el Ceará; Pandemia. 


\section{Introdução}

A abdicação de antigas certezas implica um confronto com os nossos medos mais antigos e profundos. A nossa consciência é sedimentada pela acumulação de convicções. Não podia ser de outro modo: temos que estar certos de que o que aprendemos é uma ferramenta segura para um mundo inseguro (Couto, 2016, p. 4).

Dezembro de 2019 tornou-se o marco de tempos incertos que afetaram/afetam a população mundial de modo incalculável, seja no tocante à perda de vidas e liberdade e/ou ao extenso período o qual se delongou/delonga a pandemia de COVID-19. Foi no referido mês que, na China, foram registrados os primeiros casos de infecções respiratórias por coronavírus do tipo SARS-CoV-2. Vírus que se espalhou rapidamente e acarretou na declaração de estado pandêmico, pela Organização Mundial de Saúde (OMS), em março de 2020. A transmissibilidade elevada obrigou a adoção de medidas de distanciamento social, que impactaram o modo de viver e se relacionar em sociedade, com severas implicações econômicas, sociais, emocionais, etc.

Passou-se a conviver, diariamente, com a dúvida e a incerteza sobre quando e como seria possível retomar o estado de "normalidade" anterior à disseminação do vírus SARS-Cov-2. E, conforme destacado pelo poeta moçambicano Mia Couto, na epígrafe acima, a perda de referências faz com que o ser humano precise lidar com seus medos, todavia, não se é habituado a aceitar tranquilamente essas sensações e lidar com as emoções que lhes são inerentes. Nesse contexto, uma das grandes incógnitas da atualidade reside em compreender os efeitos deste momento pandêmico no modo como a sociedade é organizada e sobretudo nas pessoas, em suas emoções e estado psíquico, de modo geral.

Segundo Morin (2003, p. 15), “[...] o ser humano é a um só tempo físico, biológico, psíquico, cultural, histórico e social [...]". Sob esse ponto de vista, é possível compreender o quanto modificações em um desses âmbitos implica diretamente nos demais. Nesse contexto, ao considerar as abruptas mudanças às quais a raça humana foi submetida nos últimos tempos, mostra-se imprescindível a realização de estudos que analisem a reestruturação dos diferentes setores da sociedade, em decorrência da pandemia de COVID-19, e suas reverberações nos diferentes aspectos que constituem o ser humano.

O foco deste ensaio situou-se no âmbito educacional, com interesse especial no modo como os jovens lidaram com o Ensino Remoto Emergencial (ERE), pois é sabido que o isolamento social promoveu (des)construções nas concepções de ensino e a aprendizagem e levar-se-á um longo período para averiguar a dimensão do impacto dessas mudanças. O lócus de interesse desse estudo reside na realidade cearense. Contexto no qual a implantação do ERE ocorreu em momentos distintos, a depender do nível de ensino e/ou município no qual as instituições educacionais estavam localizadas. Nesse cenário, os estudantes vivenciaram diferentes situações, dentre as quais podem ser destacadas: o acesso e o não acesso ao ERE.

Por conseguinte, este trabalho foi estruturado de modo a buscar respostas para os seguintes questionamentos: Os estudantes cearenses tiveram acesso ao ERE? Como foi a adaptação desses estudantes ao ERE? Quais os impactos dos estudos domiciliares e dos fatores emocionais, na aprendizagem desses estudantes? Quais foram as expectativas em relação ao retorno das atividades presenciais? Esses questionamentos serviram de base para a construção do objetivo deste estudo, que consiste em compreender como os estudantes cearenses que possuem recursos tecnológicos e internet vivenciaram as adaptações aos estudos domiciliares, por meio ou não do ERE, em termos emocionais e de aprendizagem.

O percurso metodológico adotado nesta investigação fundamentou-se em uma abordagem mista e foi caracterizado, quanto ao método, como um estudo de caso. Os sujeitos da pesquisa foram 1317 estudantes cearenses vinculados tanto à Educação Básica como ao Ensino Superior das redes de ensino pública e privada. Os dados foram coletados por meio de questionário produzido no Google Forms e compartilhado em redes sociais, cuja análise considerou instrumentos qualitativos (análise de conteúdo) e quantitativos (escala de Lickert e cálculo do ranking médio).

Fundamentado nos pressupostos acima descritos e na compreensão de que a aprendizagem tem relação direta com o âmbito afetivo, a próxima subseção foi estruturada de modo a discutir, com base na literatura da área, sobre algumas teorias 
que abordam a relação entre aprendizagem e afetividade, considerando como pano de fundo o contexto atual, de disseminação da COVID-19, e suas implicações no cenário educacional.

\section{Aprendizagem e Afetividade em Tempos de Incerteza}

A partir dos estudos de Vygotsky, sobre o desenvolvimento humano, é sabido que os processos psicológicos cognitivos e afetivos são determinados pelo ambiente cultural e social (Rego, 2014). Nesse contexto, é precípuo diferenciar emoção e afetividade. O primeiro diz respeito ao componente biológico do comportamento humano, ou seja, reações de ordem física, enquanto a afetividade envolve uma compreensão mais ampla. Para Wallon (2007), embora a afetividade tenha raízes biológicas também possui intrínseca uma função social e diz respeito à capacidade do ser humano de ser afetado negativa ou positivamente por eventos externos (o olhar do outro, uma informação que recebe do meio) e internos (fome, medo, alegria, raiva). Assim, a emoção e os sentimentos são modos de expressão da afetividade.

Para Wallon (2007), a vida psíquica é formada por três dimensões - motora, afetiva e cognitiva -, que coexistem e atuam de modo integrado, assim, aquilo que é conquistado em um plano atinge o outro mesmo que não se tenha consciência disso. Nesse contexto, questiona-se o quanto e como mudanças na rotina, no âmbito social e no modo de ensinar e aprender, em decorrência da pandemia de COVID-19, têm afetado os jovens e sua aprendizagem. Menezes e Francisco (2020) validam essa compreensão ao destacarem que uma das preocupações atuais reside nos aspectos afetivos provocados e/ou intensificados pela pandemia em relação às mudanças vivenciadas pela sociedade de modo geral e para públicos específicos como estudantes e docentes, de diferentes contextos.

Ante o exposto, compartilha-se da compreensão de Monteiro et al. (2014) acerca da importância da afetividade no âmbito educacional, no modelo virtual. Esses autores corroboram as perspectivas defendidas por Henry Wallon de que afetividade não pode ser entendida como sinônimo de "sentimento", visto que envolve se colocar em estado de atenção permanente às peculiaridades dos alunos e aos sentidos do afeto no processo pedagógico. Perspectiva que, ao ser inserida no contexto atual, de adoção do ERE, remete à necessária atenção ao modo como os estudantes foram/são afetados pelas diferentes mudanças inseridas em sua rotina e os reflexos disso no seu modo de se relacionar com os outros e com a aprendizagem.

Estudos evidenciam que o contexto pandêmico mobilizou a necessidade do ser humano lidar com emoções e sentimentos diversos, por vezes contraditórios, ou seja, aspectos afetivos que implicam diretamente em seu modo de ser, viver, se relacionar e aprender. Assim, o âmbito afetivo é potencializado pelo distanciamento social e tem implicações nos processos psicológicos das pessoas, de modo que, conforme apontado por Menezes e Francisco (2020), as instituições escolares e o uso das TDIC exerce papel relevante como estratégia para amenizar os efeitos negativos que o distanciamento social provoca no ser humano. De modo concomitante, mostra-se premente enfatizar a faceta fria dessa realidade mediada pelas tecnologias, que pode gerar estresse, ansiedade, medo, angústia, dentre outros sentimentos/emoções nos estudantes.

Um dos questionamentos que emerge dessa realidade envolve o modo como as múltiplas questões afetivo-emocionais têm influenciado a aprendizagem escolar, nesse momento pandêmico, ou seja, como o contexto atual, seja de modificações na estrutura educacional ou de insegurança, medo e de extensas mudanças sociais, têm afetado os jovens. Alguns estudos já foram desenvolvidos, na busca por compreender aspectos envoltos nesta problemática, dentre os quais destaca-se o trabalho de Menezes e Francisco (2020), que buscou analisar impactos sociais e afetivos sobre os processos de ensino e aprendizagem gerados pela pandemia de COVID-19. Esses autores identificaram a necessidade de se planejar estratégias para lidar com os impactos da pandemia para professores, estudantes e gestão educacional, e destacam que esses impactos são afetivos e sociais e envolvem a complexidade dos contextos em que as pessoas estão inseridas. 
Corrobora-se com a perspectiva desses autores e acrescenta-se que embora os estudantes façam parte de uma geração mais adaptada às tecnologias, é consenso que eles sentiram essa mudança ab-ruptu. Destarte, consoante as palavras de Médici et al. (2020, p. 138), "[...] independente da faixa etária, etapa de escolarização ou modalidade de ensino, as interferências são significativas". Os autores ressaltam ainda os impactos para os estudantes das transições entre Ensino Fundamental e Médio, possíveis ingressantes no Ensino Superior, que estão finalizando ciclos e iniciando novos.

Em síntese, é consensual que os impactos dessa ação emergencial de adoção do ensino remoto ainda serão sentidos e reavaliados por algum tempo. Portanto, esta pesquisa traz alguns contributos para essa discussão, mediante apresentação do recorte da realidade de um estado brasileiro, e apresentação das impressões dos estudantes acerca de suas experiências nos estudos domiciliares, com ênfase na relação entre ensino, aprendizagem e afetividade.

\section{Metodologia}

O presente estudo é caracterizado, quanto ao método, como um estudo de caso, haja vista que busca analisar um fenômeno particular, levando em conta seu contexto e suas múltiplas dimensões, além de demandar a necessidade da análise situada e em profundidade (André, 2013). Quanto aos objetivos, trata-se de um estudo descritivo, visto que tem como objetivo primordial a descrição das características de determinada população ou fenômeno, bem como o estabelecimento de relações entre variáveis (Gil, 2002).

Fundamenta-se, ainda, em uma abordagem mista, visto que preocupou-se, de modo concomitante, em mensurar os percentuais de respostas dos estudantes (quantitativa) e analisar qualitativamente as respostas obtidas. Os olhares quali e quanti se assumem, portanto, como complementares, no intuito de enriquecer o estudo, pois conforme destacado por Santos et al. (2017), a abordagem mista envolve uma questão específica mediante a utilização de métodos diferentes, buscando complementaridade dos resultados.

Os estudantes cearenses foram o público-alvo deste estudo. Participaram 1317 estudantes, que foram agrupados conforme o nível e a rede de ensino, do seguinte modo: Educação Básica Privada (EBPR); Educação Básica Pública (EBPB); Ensino Superior Privado (ESPR) e Ensino Superior Público (ESPB).

A coleta de dados ocorreu por meio de questionário, que, de acordo com Gil (2002), tem a vantagem de obter respostas de um grande número de pessoas, mesmo geograficamente distantes. Esse fator garante o anonimato dos sujeitos, dessa maneira não expõe os participantes às opiniões do pesquisador. O questionário foi elaborado utilizando a ferramenta Google Forms, cujo acesso ao documento foi permitido por meio de link, e a divulgação da pesquisa ocorreu mediante o uso da rede social Instagram e o link foi compartilhado, principalmente, a partir de grupos de WhatsApp. O questionário ficou disponível entre os dias 16 e 30 de junho de 2020 e continha um conjunto de perguntas para os estudantes com acesso ao ERE e outro conjunto para os que não realizaram o ERE durante o isolamento social.

O tratamento dos dados qualitativos ocorreu por meio da análise de conteúdo proposta por Bardin (2011), com uma proposta de categorização emergente, na qual as categorias surgem do que emerge na leitura dos relatos. De acordo com Oliveira (2011), esse método compõe um conjunto de técnicas com o objetivo de enriquecer as leituras e identificar mensagens intrínsecas ao objeto de estudo, ou seja, busca evidenciar o que está em segundo plano. Ademais, o programa WorldCloud foi utilizado para construir uma nuvem de palavras, destacando os termos mais utilizados pelos estudantes em suas expressões.

Os dados quantitativos foram organizados, no decorrer deste ensaio, por meio de gráficos, quadros e tabela. Vale ressaltar que, no questionário, as perguntas "Em termos de estudos, como você avalia o período de isolamento domiciliar para a sua aprendizagem?" e "Como avalia a sua adaptação ao ensino remoto emergencial?" foram construídas no formato da escala de Likert, portanto, as análises foram realizadas por meio do cálculo do ranking médio (Bonici \&Araújo Júnior, 2011). Esse 
cálculo consiste na média ponderada das respostas, considerando a frequência. Para a aplicação, valores de 1 a 5 foram atribuídos às respostas, onde 1 correspondia a menor satisfação e 5 a maior satisfação, com a situação referida na pergunta.

\section{Resultados e Discussão}

\subsection{Caracterização dos estudantes e o acesso ao ERE}

Os 1317 estudantes cearenses participantes deste estudo foram classificados segundo os critérios de níveis de ensino e tipos de rede. Os resultados da caracterização estão apresentados na Quadro 1.

Quadro 1. Caracterização dos estudantes quanto ao tipo de rede e nível de ensino.

\begin{tabular}{|c|c|c|}
\hline $\begin{array}{c}\text { Nível/ } \\
\text { Rede } \\
\text { EBPR }\end{array}$ & Valor absoluto & Valor relativo (\%) \\
\hline EBPB & 89 & 6,76 \\
\hline ESPR & 808 & 61,35 \\
\hline ESPB & 108 & 8,20 \\
\hline TOTAL & 312 & 23,69 \\
\hline
\end{tabular}

Fonte: Elaborada pelos autores.

É perceptível que a amostra investigada é composta, em sua maioria, por alunos oriundos da Educação Básica Pública (EBPB) do estado do Ceará, embora haja extratos representativos dos demais níveis e modalidades de ensino. Diante da caracterização desta amostragem, os estudantes foram categorizados a partir da declaração de ter tido acesso ou não às atividades letivas por meio do ERE. Os dados obtidos estão dispostos no Gráfico 1.

Gráfico 1. Acesso dos estudantes ao ERE por tipo de rede e nível de ensino.

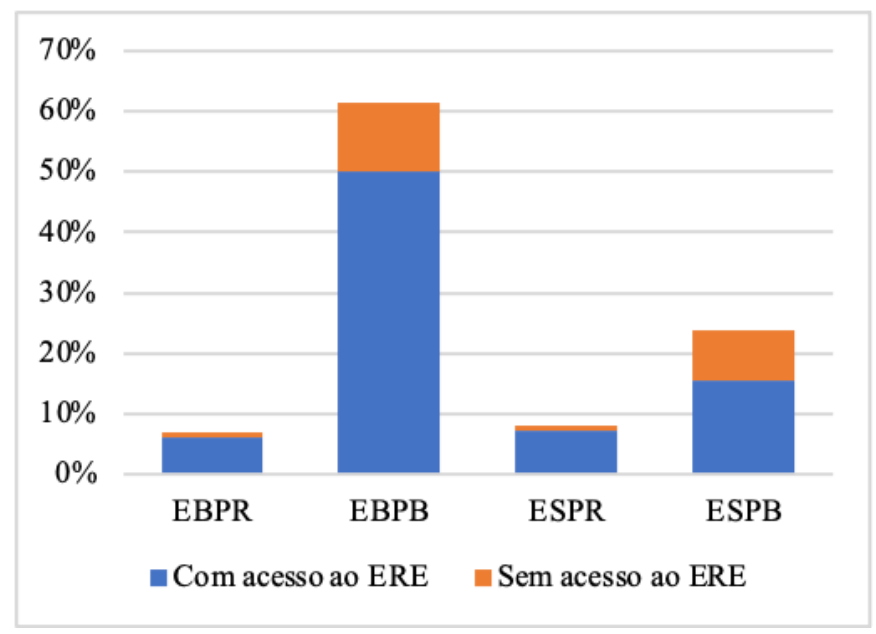

Fonte: Elaborada pelos autores.

Ao analisar os dados, verificou-se que houve a oferta do ERE em todos os tipos de rede e modalidades de ensino cearenses. Ademais, o percentual de estudantes com acesso representou mais da metade da amostragem (1040 alunos). Salienta-se, todavia, que os estudantes das instituições da rede pública representaram os maiores percentuais relacionados à não continuidade das atividades de ensino, na modalidade remota.

É sabido que houve disparidades na oferta do ERE nas instituições de ensino. Fato diretamente relacionado às condições físicas e financeiras. Na rede privada, a maioria das escolas, faculdades, centros universitários e universidades 
possuem recursos financeiros e apoio técnico, inclusive algumas delas já utilizavam ferramentas de educação a distância cotidianamente. Isso facilitou para que os professores recebessem formação e dessem continuidade às atividades de ensino.

Em contrapartida, as instituições públicas lidam com sérios problemas no que diz respeito à estrutura física, financeira e ao suporte técnico. As escolas públicas estaduais iniciaram rapidamente as ações didáticas, e mesmo com todos os desafios e limitações de recursos, principalmente dos estudantes, o ERE foi ofertado. Algumas universidades públicas estaduais, no entanto, enfrentaram grandes dificuldades para dar continuidade às atividades de ensino, seja por meio do ERE ou na preparação para o retorno das atividades presenciais. Em consequência disso, até o mês de outubro do ano de 2020 não havia oferta de ensino nas referidas universidades. Dentre os principais fatores para o fato exposto, estão as questões financeiras e as desigualdades sociais dos estudantes.

Nessa direção, ressalta-se o fato de, nas universidades públicas, existirem entraves voltados à disponibilidade de recursos tecnológicos e de internet pelos estudantes. Além disso, as questões econômicas e sociais que afetaram as famílias trouxeram consequências ao desempenho das atividades educacionais para professores e alunos. Consoante às ideias de Moreira e Aragão (2020), a implementação do ERE, nas universidades públicas, aumenta a desigualdade, pois dados apresentados pela Associação Nacional dos Dirigentes das Instituições Federais de Ensino Superior (ANDIFES) em 2019, mostraram que $70 \%$ dos estudantes das universidades federais pertencem ao grupo de baixa renda. Arruda (2020) acrescenta outros fatores ao cenário descrito, tais como falta de acesso de uma parte da população a recursos tecnológicos e dificuldades no acompanhamento das aulas por parte dos atores educacionais.

As questões seguintes, dispostas no questionário, foram divididas em dois blocos. Um grupo de questões foi respondido pelos estudantes que tiveram acesso ao ERE e outro bloco de perguntas foi respondido por aqueles que não tiveram acesso ao ensino remoto. Desse modo, a discussão deste trabalho também foi dividida em subseções, conforme disposto a seguir.

\subsection{Estudantes cearenses com acesso ao ERE}

Um grupo de 1040 estudantes com acesso ao ERE responderam a um conjunto de perguntas, que, dentre outros fatores, investigou o perfil de acesso aos recursos eletrônicos e internet no ERE. Os resultados estão apresentados no Gráfico 2.

Gráfico 2. Condições de acesso a eletrônicos e internet dos estudantes no ERE.

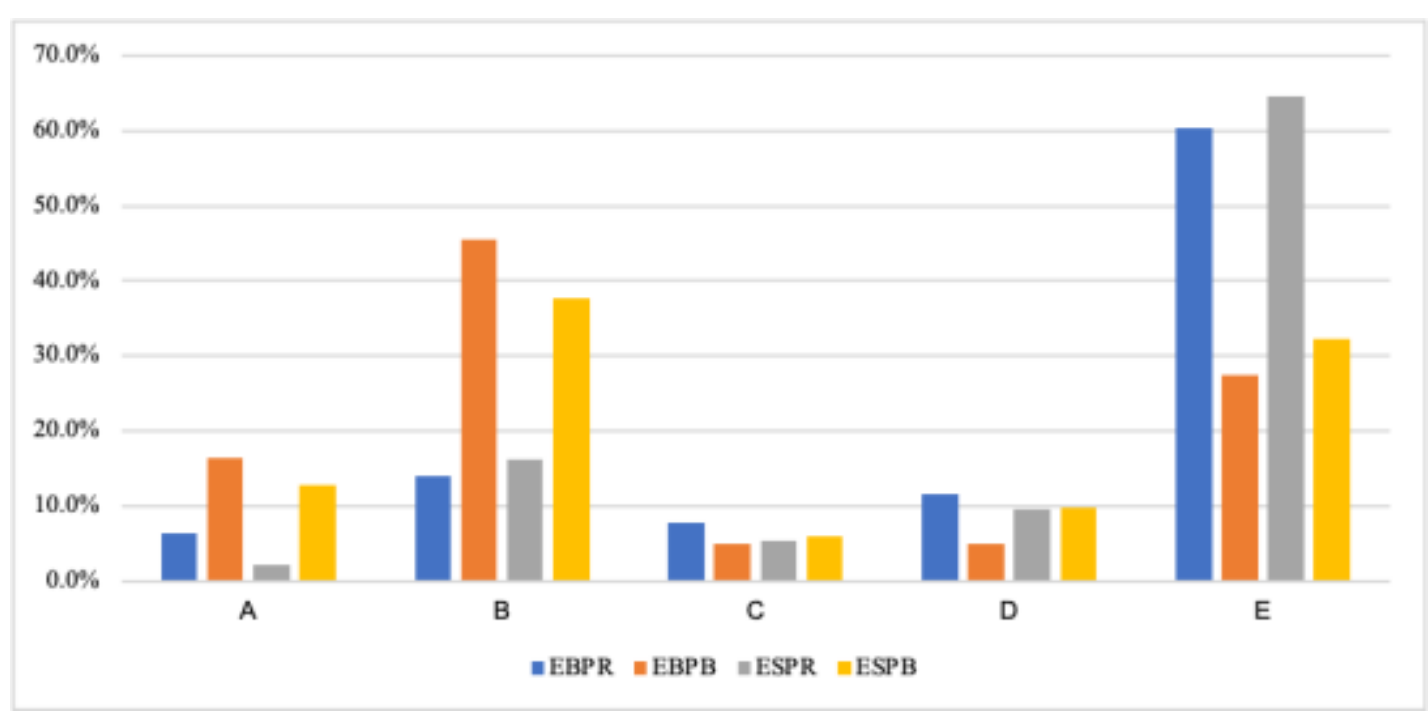

. Legenda: A - Possuo apenas celular e uso internet de vizinhos ou Wi-Fi livre; B - Possuo apenas celular e internet de dados móveis/Wi-Fi; C - Possuo celular e computador, com grandes limitações de internet; D - Possuo celular e computador, com boa capacidade de internet, mas ainda insuficiente para os estudos domiciliares; E - Possuo celular e computador, com boa capacidade de internet, suficiente para os estudos domiciliares. Fonte: Elaborada pelos autores 
Os dados apresentados neste Gráfico mostram as desigualdades de acesso aos recursos tecnológicos e internet nas redes pública e privada. Nas condições A e B, cujas características representam as condições mais delicadas para os estudantes, o maior percentual pertence às instituições públicas, principalmente da Educação Básica. Já na condição E, favorável aos estudos domiciliares, os estudantes da rede privada apresentam percentual acima de $60 \%$.

$\mathrm{Na}$ sequência, os estudantes foram questionados se precisaram adquirir equipamentos eletrônicos ou internet, ou ampliar o pacote de internet para atender as demandas do ERE. Os dados revelaram que 333 (32\%) dos 1040 estudantes com oportunidade de estudar por meio do ERE compraram equipamentos eletrônicos ou ampliaram o pacote de internet para realizar as atividades.

Segundo descrições de Lobo (2020), os resultados da pesquisa intitulada TIC Educação 2019 demonstraram que apenas $28 \%$ das escolas localizadas em áreas urbanas possuíam plataformas de aprendizagem a distância, dentre as quais $14 \%$ em escolas urbanas públicas e 64\% particulares urbanas. Em 2018, esses valores eram de 17\% e 47\%, respectivamente. Esses dados mostram o crescimento da desigualdade de condições entre as instituições de ensino e, consequentemente, entre os estudantes.

A TIC Educação 2019 revelou ainda que o acesso exclusivo pelo celular foi maior entre alunos das regiões Norte (25\%) e Nordeste (26\%) e de estudantes das escolas públicas urbanas (21\%) (Lobo, 2020). Esses dados ratificam os achados da presente pesquisa, pois o percentual de estudantes que declararam ter acesso apenas pelo celular foi maior nas instituições públicas.

Outro dado relevante diz respeito aos resultados da oitava edição da pesquisa TIC Kids Online. Sobre esse estudo, Prescott (2020) ressalta que foi evidenciado que 4,8 milhões de crianças e adolescentes, de 9 a 17 anos, vivem sem acesso à internet em suas residências. A limitação de acesso à internet ocorre, sobretudo, nas populações de áreas rurais e das regiões Norte e Nordeste.

Nas perguntas seguintes, foi solicitado aos estudantes que avaliassem sua adaptação ao ERE, bem como sua aprendizagem nesse novo modelo de ensino. É precípuo destacar que, no Ceará, a maioria das instituições iniciou o ERE no mês de abril, então em meados de junho, período da coleta de dados, já foi possível avaliar esses aspectos. Desse modo, para a tabulação dos dados referentes a essas duas questões recorreu-se ao cálculo de ranking médio. Foram atribuídos valores de 1 a 5 às respostas obtidas, onde 1 correspondia a menor satisfação e 5 a maior satisfação, com a situação referida, e, a seguir, no Quadro 2, estão dispostos os resultados obtidos.

Quadro 2. Resultados do cálculo do ranking médio da adaptação e da avaliação da aprendizagem dos estudantes no ERE.

\begin{tabular}{|l|c|c|}
\hline Nível/Rede & Adaptação & Aprendizagem \\
\hline EBPR & 2,10 & 2,19 \\
\hline EBPB & 2,11 & 2,23 \\
\hline ESPR & 2,12 & 2,34 \\
\hline ESPB & 2,09 & 2,32 \\
\hline
\end{tabular}

Fonte: Elaborada pelos autores.

Os extratos acima apresentados demonstram que, independentemente da rede e nível de ensino, a média dos valores relativos à avaliação da adaptação e da aprendizagem não chegou à metade do que se considera a nota máxima, o valor 5 . A média correspondente a adaptação ao ERE, nos diferentes níveis e tipos de rede, variou minimamente, isso significa que as dificuldades foram semelhantes para todos. Vale ressaltar alguns aspectos, tais como: manuseio das interfaces virtuais, tempo frente às telas e necessidade de concentração, diminuição da interação, ausência do contato com os demais integrantes das turmas, entre outros. 
A concentração dos estudantes é um dos maiores desafios no ERE, os autores Xiao \& Li (2020) citam a dificuldade de manter os alunos atentos, inclusive com a manutenção do link de acesso contínuo aos conteúdos, os desafios dos professores por não poderem efetuar adequadamente as leituras corporais dos estudantes e a manutenção de um ambiente interativo.

Salienta-se, ainda, que a menor média no quesito aprendizagem ocorreu na rede privada da Educação Básica, para a qual é atribuída uma boa condição estrutural e financeira para o gerenciamento do ensino remoto. Esse fato evidencia que a aprendizagem está além das condições estruturais, embora elas sejam importantes.

A impressão dos estudantes sobre a própria aprendizagem, no entanto, mostra que eles a consideram abaixo da média, em todos os níveis e tipos de rede. Um estudo realizado por Médici et al. (2020) trouxe a percepção dos estudantes do Ensino Médio acerca das atividades remotas. Os resultados revelaram que 39,6\% dos estudantes pesquisados em uma escola pública declararam ter dificuldades na compreensão do conteúdo, considerando-os confusos.

Os estudos de Piaget mostram que a aprendizagem acontece em função da experiência obtida de modo ordenado. Nessa direção, ressalta-se ainda que a afetividade e a interação social também contribuem para esse resultado, portanto, esses três fatores precisam ser desenvolvidos concomitantemente para facilitar a construção do conhecimento (Moura et al., 2018).

As consequências das experiências dos estudantes para o desenvolvimento da aprendizagem, durante os estudos domiciliares, e o quanto todo esse acontecimento ainda vai reverberar após o retorno das atividades presenciais, não são possíveis de prever neste momento de incertezas. Enquanto se aguarda essa retomada das atividades presenciais, alguns aspectos relativos à aprendizagem dos estudantes podem ser destacados, tais como: as defasagens no ano corrente, o acompanhamento nas séries seguintes, as desigualdades dentro da mesma turma, as influências dos aspectos emocionais, econômicos etc.

Os valores médios encontrados sobre a adaptação e a aprendizagem foram importantes para compreender a relação dos estudantes com as tecnologias educacionais. Então, para expandir essa compreensão, foi realizado o seguinte questionamento a esses sujeitos: "Você gostaria de continuar utilizando ferramentas tecnológicas no retorno das atividades presenciais?'. Os dados estão apresentados no Gráfico 3.

Gráfico 3. Interesse no uso de tecnologias na educação após o ERE.

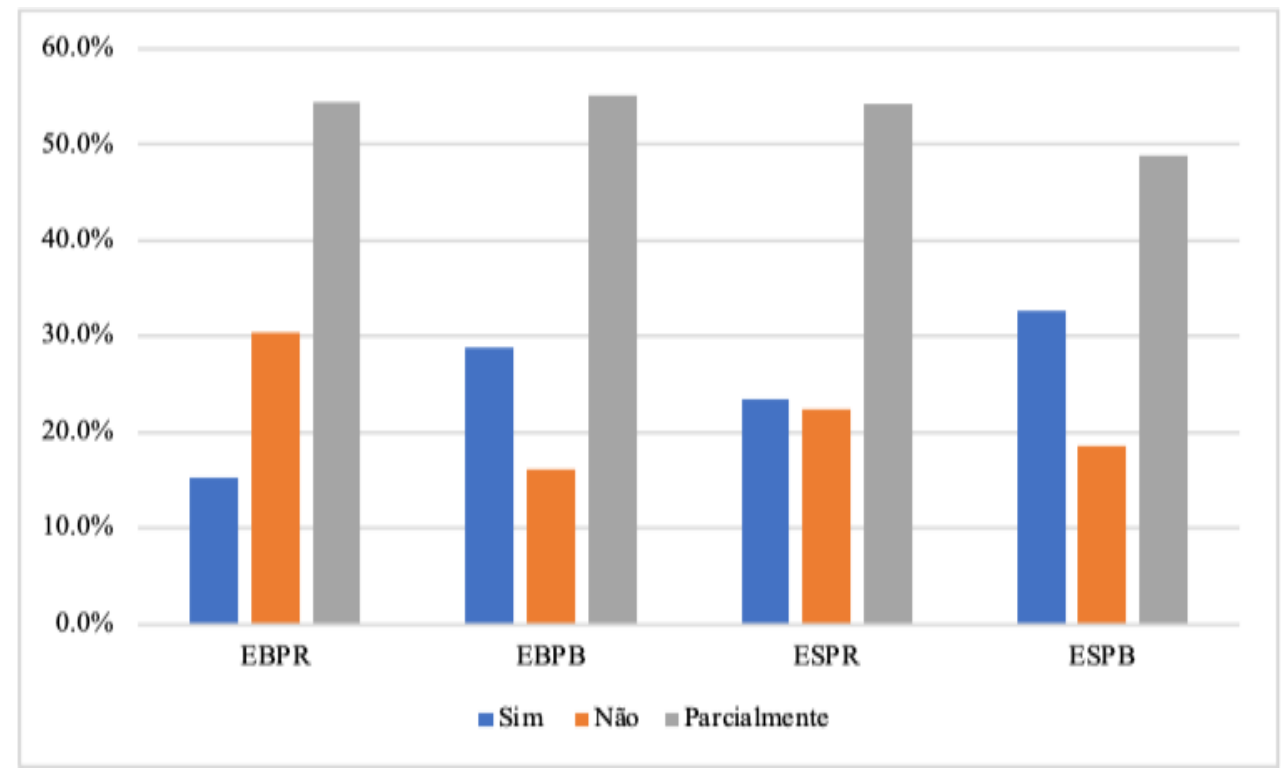

Fonte: Elaborada pelos autores. 
Os resultados revelaram o desejo pela utilização parcial das tecnologias após o ERE. Uma observação pertinente, voltando-se apenas para as condições de sim e não, refere-se ao fato de os estudantes das instituições públicas terem assinalado positivamente quanto ao uso das tecnologias após o ERE, enquanto nas escolas da Educação Básica da rede privada houve um maior percentual de alunos reprovando o uso de tais recursos após o ERE.

No estudo de Costa et al. (2015), os autores utilizam o termo nativos digitais ao tratar dos jovens, principalmente os estudantes com acesso às Tecnologias Digitais de Informação e Comunicação (TDIC). Segundo os autores, espera-se que o uso das TDIC provoque mudanças na socialização, na colaboração e compartilhamento de informações influenciando, desse modo, a aprendizagem.

Em contrapartida, as circunstâncias ocasionadas pela pandemia impulsionaram o uso excessivo das TDIC. Os estudantes passaram a interagir quase que exclusivamente por meio digital, somado a todos os outros fatores emocionais envolvidos no isolamento domiciliar, percebeu-se a presença de uma fadiga mental. Ademais, os estudantes demonstraram maior valorização dos momentos de troca presencial, inclusive das aulas, da proximidade do professor, dos colegas de classe. Todos esses aspectos provocaram um afloramento de emoções e sentimentos nas pessoas e, consequentemente, nos estudantes.

Nesta pesquisa, a influência dos fatores emocionais na aprendizagem também foi investigada, visto que, conforme ressaltado por Souza et al. (2020, p. 382), “[...] a compreensão de fatores e de ambientes ecológicos que influenciam os escolares, de forma emocional, pode colaborar para a reflexão sobre o processo de aprendizagem [...]”. Assim, numa questão dissertativa, foi solicitado que os estudantes descrevessem como as questões emocionais estavam influenciando sua relação com os estudos. Para o tratamento destes dados foi realizada uma análise quali e quantitativa, da qual emergiram as categorias dispostas no Tabela 1.

Tabela 1. Categorização das emoções dos estudantes que influenciaram nos estudos no ERE.

\begin{tabular}{l|c|c|c|c}
\hline \multirow{2}{*}{ Nível/Rede } & \multicolumn{4}{|c}{ CATEGORIAS } \\
\cline { 2 - 5 } & Ansiedade & Dispersão & Motivação & Neutralidade \\
\hline EBPR & $35,3 \%$ & $29,4 \%$ & $5,9 \%$ & $29,4 \%$ \\
\hline EBPB & $38,7 \%$ & $24,5 \%$ & $13,5 \%$ & $23,6 \%$ \\
\hline ESPR & $39,0 \%$ & $37,3 \%$ & $10,2 \%$ & $13,6 \%$ \\
\hline ESPB & $37,4 \%$ & $21,2 \%$ & $9,1 \%$ & $31,3 \%$ \\
\hline
\end{tabular}

Fonte: Elaborada pelos autores.

Os resultados apontam os altos índices de ansiedade em todos os níveis e redes, com um destaque para o ESPR onde houve também um valor expressivo de dispersão. Salienta-se que esses valores podem ser atribuídos a preocupações fora do âmbito educacional, uma vez que grande parte destes estudantes também trabalha para ajudar financeiramente em casa ou para seu próprio sustento, já que a pandemia interferiu muito na economia, principalmente nos empregos informais. Além disso, chama atenção o menor percentual de estudantes motivados serem de escolas privadas da Educação Básica. O fator neutralidade foi atribuído àqueles que não souberam responder ou que relataram não sentir nenhuma influência emocional nesse sentido.

Com o intuito de aprofundar a discussão em torno dos aspectos emocionais dos estudantes, alguns relatos foram transcritos a seguir: "A ansiedade causada pelo isolamento social provocou desmotivação e falta de interesse nos estudos" (Estudante - ESPB); “A constante preocupação com a saúde dos parentes mais próximos ofusca quase que por completo as obrigações acadêmicas; atrelado a isso as preocupações financeiras bem como de trabalho" (Estudante - ESPR).

A ansiedade é uma resposta fisiológica do ser humano às situações vivenciadas no meio onde está inserido. Dentre os sintomas, estão a inquietação, dificuldade de concentração, distúrbios do sono, fadiga, tremores etc. (Fernandes et al., 2018). Posto isso, salienta-se o quanto a aprendizagem pode ser influenciada pelos sintomas de ansiedade, ainda mais quando a 
realidade dos estudantes é de instabilidade no sustento da família, manutenção da saúde de pessoas próximas e incertezas de modo geral.

Os fatores ansiogênicos podem estar envolvidos com casos de depressão. Nessa direção, de acordo com os resultados do estudo de Fernandes et al. (2018), 30,2\% dos estudantes de um curso no Ensino Superior possuem depressão. Os autores relataram que, ao comparar tais dados com a população não universitária, os estudantes apresentaram percentuais em torno de três vezes maiores, o que pode estar associado ao ambiente competitivo e cobranças.

Por outro lado, na Tabela 1, um percentual menor de estudantes encarou este período como uma oportunidade para empenhar-se com maior afinco. Isto foi observado em relatos semelhantes ao seguinte transcrito: "Me adaptei porque me considero um estudante profissional" (Estudante - ESPB); "Tive bastante foco para conseguir me adaptar da melhor forma possível. E tenho bastante otimismo para acreditar que vai ficar tudo bem” (Estudante - EBPB).

O exame profícuo dos relatos e dos dados da Tabela 1 leva a uma reflexão sobre o quão profunda é essa relação dos fatores emocionais com o desenvolvimento das atividades discentes e, consequentemente, a concretização da aprendizagem.

Vale ressaltar que a aprendizagem pode acontecer mesmo quando o estudante não está diretamente ligado a uma instituição ou, nesse caso, quando não houve acesso ao ERE. Desse modo, mostrou-se interessante realizar uma sondagem do modo como esses sujeitos que não acessaram o ERE se relacionaram com a aprendizagem durante esse contexto de mudança no qual a sociedade está inserida.

\subsection{Estudantes cearenses sem acesso ao ERE}

Os 277 estudantes cujos relatos evidenciaram o não acesso às atividades de ensino, por não ter sido ofertado pelas instituições às quais estão vinculados, declararam como vivenciaram o período de isolamento domiciliar em relação aos estudos. Salienta-se que, embora algumas instituições não tenham aderido ao ERE para as atividades de ensino, a continuidade das ações de extensão e/ou pesquisa ocorreu por esse meio. Sobre a participação dos discentes nessas ações, os resultados encontram-se na Quadro 3.

Quadro 3. Tipos de atividades remotas ofertados pelas instituições de ensino não aderentes ao ERE.

\begin{tabular}{|l|c|c|}
\hline \multicolumn{1}{|c|}{ ATIVIDADE } & Valor absoluto & Valor relativo (\%) \\
\hline Extensão & 48 & 17,33 \\
\hline Pesquisa & 108 & 38,99 \\
\hline Nenhuma & 118 & 42,60 \\
\hline Não responderam & 3 & 1,08 \\
\hline TOTAL & 277 & 100 \\
\hline
\end{tabular}

Fonte: Elaborada pelos autores.

Os resultados apresentados mostram que quase metade dos estudantes não realizou nenhuma atividade na instituição a qual está vinculado. Já os dados relativos às atividades de pesquisa e extensão demonstram que tais eixos permaneceram em ação, mesmo com adaptações em suas rotinas para atender a legislação pertinente ao distanciamento.

No período de isolamento domiciliar, todavia, observou-se uma disseminação do conhecimento, por meio da divulgação de um grande número de cursos, videoconferências, livros digitais, entre outros. Nesse sentido, o Gráfico 4 apresenta os principais meios de estudo utilizados pelos estudantes que não tiveram acesso ao ERE, a partir de suas instituições de ensino. 
Gráfico 4. Recursos utilizados para aquisição de conhecimento durante o isolamento domiciliar.

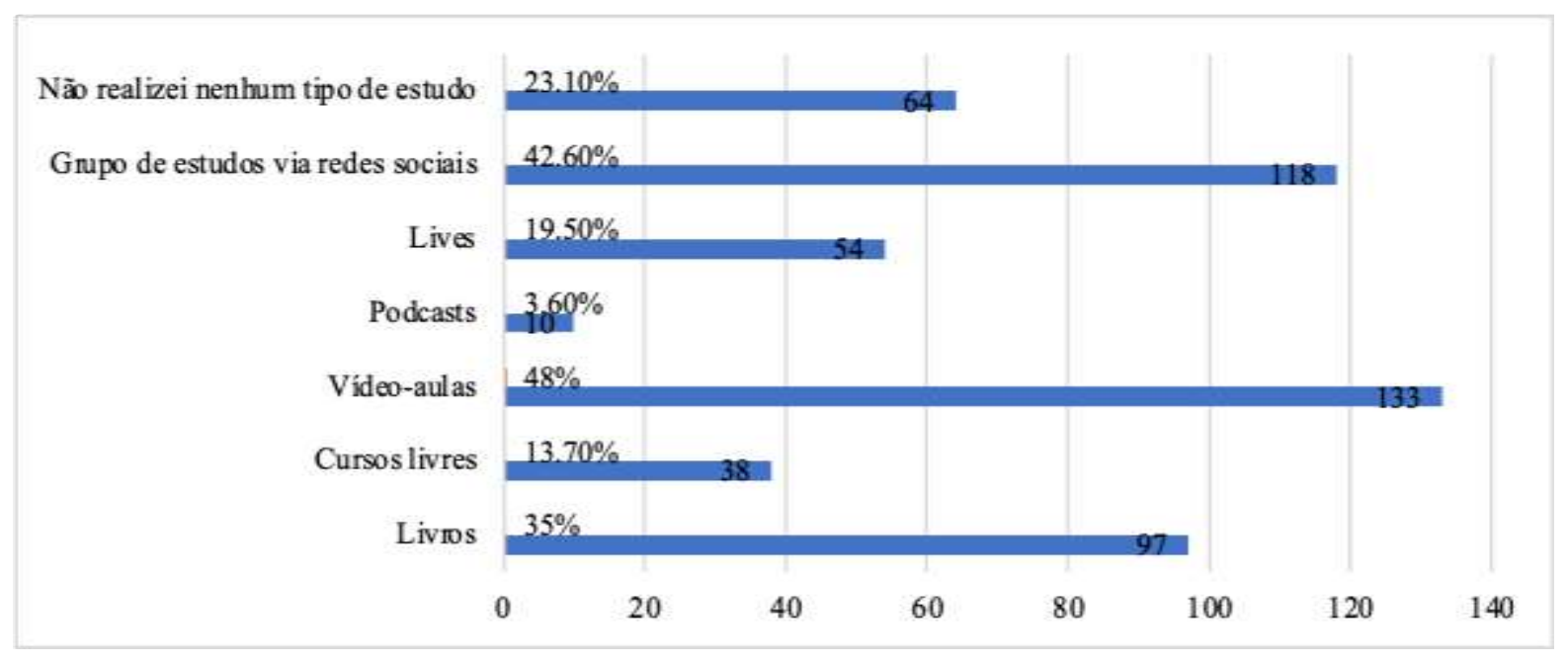

Fonte: Elaborada pelos autores.

Os dados apresentados no Gráfico 4 mostram que 64 estudantes não realizaram nenhuma atividade de estudos, seja pela instituição de ensino ou por outras fontes disponíveis nos meios digitais. Os demais utilizaram principalmente vídeo-aulas, grupos de estudos via redes sociais e livros.

A utilização de vídeo-aulas de professores denominados de youtubers, neste período, foi extremamente relevante. Alguns docentes já possuíam canais de comunicação online, outros, entretanto, iniciaram esse contato durante a pandemia. Moreira et al. (2020, p.352) dizem que: “[...] essa foi uma fase importante de transição em que os professores se transformaram em youtubers gravando vídeo-aulas e aprenderam a utilizar sistemas de videoconferência". Nesse contexto, embora haja muito a ser feito na perspectiva de incorporação de uma educação em rede de qualidade, esse movimento iniciático no uso constante de tecnologias pelos professores, de modo geral, contribui para uma mudança de paradigmas.

O aplicativo de comunicação WhatsApp possibilitou as trocas, pois promove a interação, o compartilhamento de materiais audiovisuais, documentos e, ainda permite a formação de grupos. Portanto, essa interface digital contribuiu fortemente para as atividades de ensino durante a pandemia. Mas, além disso, outras redes sociais foram utilizadas para grupos de estudos, como os grupos fechados do Facebook. Vale ressaltar que, embora haja todo um desenvolvimento tecnológico, os livros permanecem como um eixo no que diz respeito ao ensino-aprendizagem, principalmente com o uso dos e-books.

No tópico seguinte, alguns resultados de estudante com ou sem acesso ao ERE serão comparados, haja vista a pertinência de tais dados e o quanto propiciam reflexões.

\subsection{Relações entre dados dos estudantes com e sem acesso ao ERE}

Os estudantes relataram como foi a sua relação com as instituições de ensino as quais possuem vínculo. Algumas destas descrições estão apresentadas no Quadro 4. 
Quadro 4. Estudantes e as instituições de ensino.

\begin{tabular}{|l|l|}
\hline Nível/Rede & Relatos dos estudantes \\
\hline EBPR & $\begin{array}{l}\text { "Distante" } \\
\text { "A minha relação com a minha instituição está sendo favorável. Em questão de aprendizagem não } \\
\text { está sendo de muito proveito devido ao isolamento e outras questões" }\end{array}$ \\
\hline EBPB & $\begin{array}{l}\text { "Péssima, não estou conseguindo acompanhar os conteúdos, aulas EAD* são ruins" } \\
\text { "Está sendo um pouco ruim, pois nas nossas casas nós não temos a mesma disposição de estudar } \\
\text { como na escola" } \\
\text { "Todos os professores se dedicam e os alunos também! Mas com toda certeza está todo mundo meio } \\
\text { cansado, pra baixo e etc." }\end{array}$ \\
\hline ESPR & $\begin{array}{l}\text { "Bom, a faculdade está procurando dar o máximo para fornecer conteúdo, para que não nos } \\
\text { prejudiquemos nesta pandemia e não atrasemos os estudos" } \\
\text { "Eles estão se fazendo bem presentes, dando muito apoio! Porém a aprendizagem está ruim" }\end{array}$ \\
\hline ESPB & $\begin{array}{l}\text { "Não há nenhuma relação" } \\
\text { "Sinto-me deslocada, não sei muito sobre projetos de extensão da universidade ao todo, vejo que só } \\
\text { "Péssimo queria aulas remotas" } \\
\text { "Bem, estão fazendo atividades, provas e já estão até dando nota" }\end{array}$ \\
\hline
\end{tabular}

*Educação a Distância. Fonte: Elaborada pelos autores.

Os relatos no Quadro 1 mostram o quanto os estudantes foram impactados pela pandemia. Enquanto uns descreveram que as aulas em EAD são ruins, outros queriam ter tido aulas no modo remoto, pois não tiveram acesso a essa ferramenta. Com relação às instituições, percebeu-se que algumas estavam bem presentes, enquanto outras não conseguiram se organizar para oferecer a assistência necessária aos seus discentes. Ademais, com ou sem apoio das instituições, os estudantes demonstraram insatisfação com a aprendizagem.

Os estudantes com e sem acesso ao ERE, por meio das instituições de ensino, apresentaram queixas semelhantes, tanto acerca da aprendizagem, quanto nos relatos sobre a influência dos fatores emocionais. O Gráfico 5 traz uma comparação da avaliação dos estudantes acerca da aprendizagem e dos fatores emocionais durante o período do isolamento domiciliar.

Gráfico 5. Relação da aprendizagem e dos fatores emocionais dos estudantes no isolamento domiciliar.

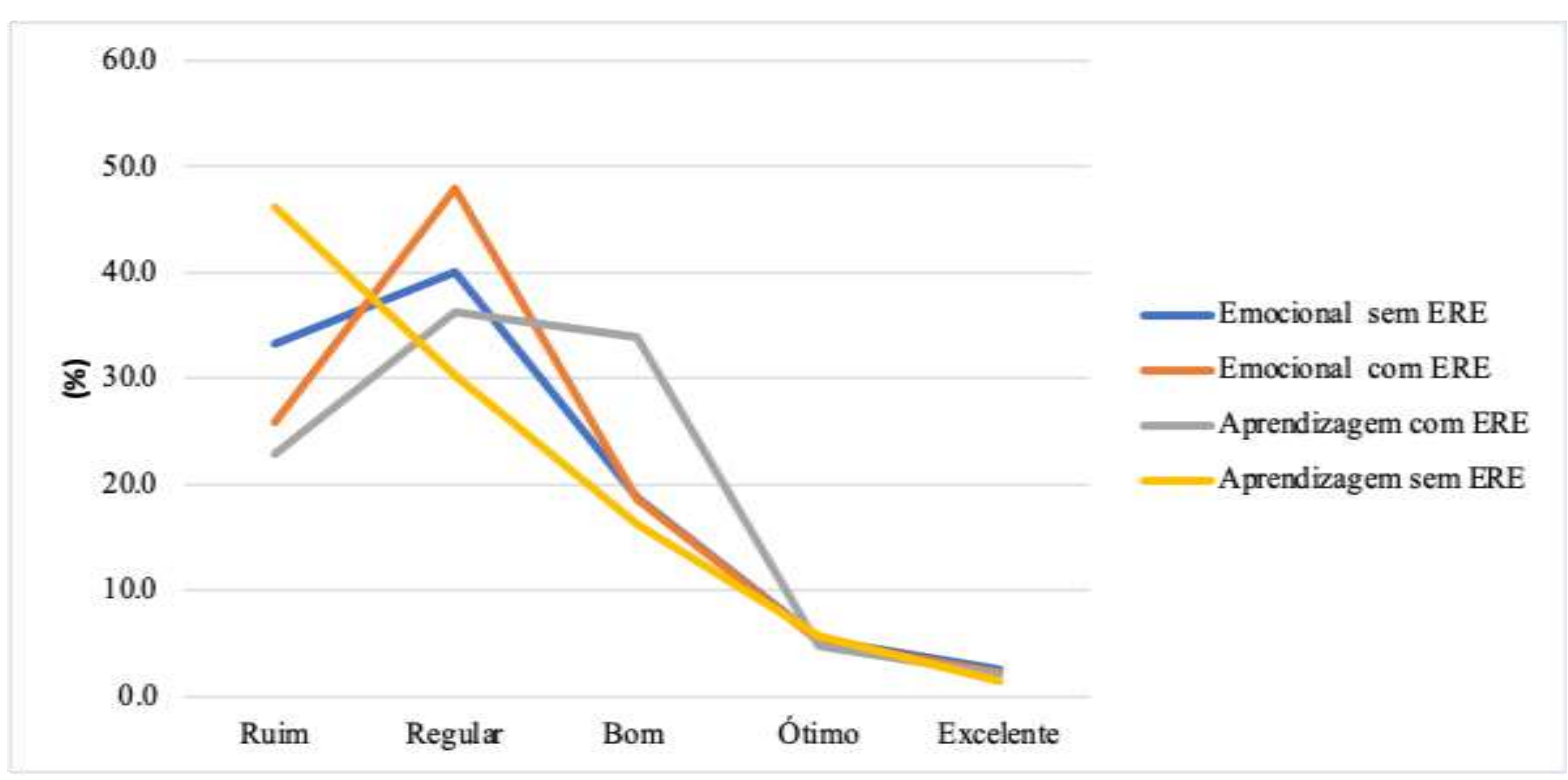

Fonte: Elaborada pelos autores.

De acordo com o Gráfico 5, a comparação entre as linhas da aprendizagem, com e sem o ERE, demonstra que os resultados de ótimo e excelente são praticamente iguais, ou seja, um percentual pequeno de estudantes conseguiu ter um desempenho favorável, independentemente de ter ou não acesso ao ERE. Em contrapartida, as variações nos demais quesitos 
evidenciaram que o ERE foi um importante facilitador da aprendizagem, mesmo com as contradições envolvidas em sua implementação.

Os resultados dos fatores emocionais nos estudos domiciliares mostram que os percentuais da condição "Ruim" foram maiores nos estudantes sem acesso ao ERE. De modo geral, os maiores percentuais, tanto dos fatores emocionais quanto da aprendizagem, encontram-se nas condições "Ruim" e "Regular", ou seja, os estudantes, de modo geral, não avaliaram positivamente este período nesses dois aspectos.

Os fatores emocionais influenciam no retorno às atividades presenciais. Isso foi evidenciado ao se tratar do retorno às atividades presenciais, onde foram obtidos os seguintes dados: 45,1\% afirmam ser receosos com o retorno presencial às instituições de ensino; 29,6\% parcialmente e apenas 25,3\% declararam não ter medo dessa iniciativa. Ainda nesse sentido, 97,4\% dos estudantes avalia como essencial o uso de medidas de segurança sanitária para o retorno nas instituições de ensino.

Nas análises de ambos os dados acima citados, os estudantes com ou sem receio de retornar desejaram a manutenção das medidas preventivas. As discussões acerca do retorno às instituições de ensino têm trazido esse ponto como um entrave, especialmente na Educação Básica: os estudantes obedecerão às medidas sanitárias e de distanciamento? Como serão os índices de disseminação da Covid-19 após o retorno das atividades letivas presenciais? Esses e outros questionamentos têm permeado o meio educacional.

Os estudantes foram inquiridos sobre o "novo normal" a ser vivenciado nas instituições após o ERE, a partir das narrativas uma nuvem de palavras foi construída e está demonstrada na Figura 1.

Figura 1. Nuvem de palavras dos relatos dos estudantes sobre o "novo normal” após o ERE.

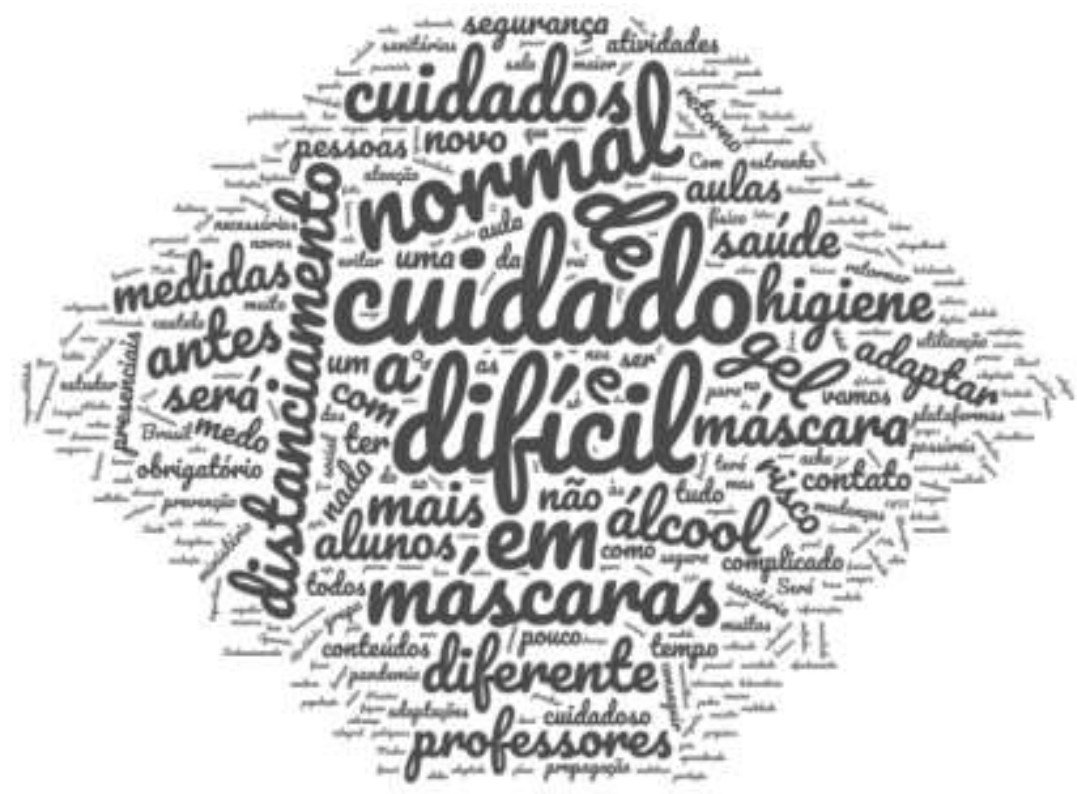

Fonte: Elaborada pelos autores.

Ao observar a imagem, as palavras mais enfatizadas pelos estudantes retratam o contexto vivenciado no período de pandemia. Desse modo, os termos difícil, distanciamento, máscaras, cuidado estão compondo o vocabulário das pessoas, inclusive dos estudantes. Para além da análise por meio da nuvem de palavras, alguns relatos dos estudantes foram transcritos: "Acredito que vai ser uma tarefa muito difícil, pois nem todo mundo vai ter a mesma responsabilidade e o mesmo pensamento em respeitar as medidas do novo normal” (Estudante - ESPR); “Ainda terá um afastamento social e receio de multidões, acho que vou evitar ficar muito tempo em grupos" (Estudante - EBPB). 
As palavras mais constantes no vocabulário dos estudantes, mediante essa temática, juntamente com os relatos descritos, mostraram a sensação de insegurança e incertezas quanto ao "novo normal". Segundo Daniel (2020), as instituições devem dar prioridade à tranquilidade dos alunos e dos pais, por meio de uma comunicação direcionada. Na opinião do autor, os professores podem ser melhores do que os pais para amenizar questões de ansiedade dos alunos em questão de privação.

No Ceará, as instituições de ensino, em todos os níveis e tipos de redes, elaboraram os devidos planos de retomada, contemplando as medidas sanitárias e de distanciamento, todavia o quantitativo de casos de Covid-19 ainda não permitiu o retorno das aulas presenciais para todos. Os estudantes cearenses, por sua vez, continuam aguardando como serão os direcionamentos que nortearão a educação no estado.

\section{Considerações Finais}

Amo a incerteza como amo a certeza. Mas talvez seja hoje necessário fazer um elogio faccioso a favor do que é incerto. Ao fim e ao cabo, a incerteza é um abraço que damos ao futuro. A incerteza é uma ponte entre o que somos e os outros que seremos (Couto, 2016, p. 6).

O presente estudo demonstrou um panorama de como os estudantes cearenses estão vivenciando os estudos domiciliares. A partir dos resultados obtidos, pôde-se perceber que os estudantes com acesso ao ERE adaptaram-se, todavia enfrentam dificuldades no exercício da atividade discente, devido à falta de concentração, ansiedade, ausência do convívio com os outros atores educacionais, dentre outros fatores, sobretudo afetivo-emocionais. Tais decorrências, associadas à disponibilidade e qualidade dos recursos tecnológicos e internet, afetaram a aprendizagem, que, de acordo com a avaliação dos próprios estudantes, ocorre de maneira precária.

A maioria dos estudantes que não acessou as atividades de ensino por meio do ERE avaliou negativamente a aprendizagem e o emocional, durante a pandemia. Em contrapartida, mesmo com todas as controvérsias relacionadas à implementação do ERE, os estudantes com acesso apontaram contribuições desse sistema para sua aprendizagem. Infelizmente, as desigualdades sociais existentes na sociedade impedem que todos os estudantes tenham acesso ao ensino remoto, o que ressalta a importância de discussões acerca dessa nova realidade e, sobretudo, a busca por soluções plausíveis e exequíveis que contribuam para a redução dessas desigualdades dentro e fora do âmbito escolar.

Os sentimentos expressivos de receio ao se tratar do retorno às atividades presenciais reiteram as incertezas, as rotinas impregnadas de cuidados e de medo. Embora essa realidade tenha sido identificada no Ceará, sabe-se que tal retrato é comum em outros estados, inclusive em outros países. Diante desse cenário, os estudantes e as famílias aguardam como será esse retorno e quais medidas serão tomadas para minimizar os efeitos desse inesperado acontecimento para os estudantes, para as aprendizagens e para a educação como um todo. O que se sabe, até o momento, é que conforme destacado por Mia Couto, na epígrafe de abertura desta subseção, esse período de incerteza e de adequações à realidade imposta pela pandemia de COVID19 é um abraço no futuro, pois professores, alunos e o âmbito educacional, como um todo, passam por (re)significações que reverberarão permanentemente nos modos de ensinar e aprender.

Estudos posteriores poderão ser impetrados no sentido de avaliar o impacto do retorno às atividades presenciais no emocional e nas aprendizagens dos estudantes.

\section{Agradecimentos}

Aos discentes sujeitos participantes da pesquisa. 
Research, Society and Development, v. 11, n. 1, e18011125028, 2022

(CC BY 4.0) | ISSN 2525-3409 | DOI: http://dx.doi.org/10.33448/rsd-v11i1.25028

\section{Referências}

André, M. (2013). O que é um estudo de caso qualitativo em educação. Revista da FAEEBA - Educação e Contemporaneidade, 22(40), 95-103.

Arruda, E. P. (2020). Educação Remota Emergencial: elementos para políticas públicas na educação brasileira em tempos de Covid-19. Revista Em Rede, 7(1), 257-275.

Bardin, L. (2011). Análise de conteúdo. Edições 70.

Bonici, R. M. C. \& Araújo Júnior, C. F. de. (2011). Medindo a satisfação dos estudantes em relação a disciplina on-line de probabilidade e estatística. In: $17^{\circ}$ Congresso Internacional de Educação a Distância, Manaus.

Couto, M. (2016). Narrativas e incertezas. In: Volz, J. \& Prates, V. (Orgs.). Incerteza viva: processos artísticos e pedagógicos. $32^{a}$ Bienal de São Paulo. São Paulo: Fundação Bienal de São Paulo.

Costa, S. R. S., Duqueviz, B. C. \& Pedroza, R. L. S. (2015). Tecnologias Digitais como instrumentos mediadores da aprendizagem dos nativos digitais. Revista Quadrimestral da Associação Brasileira de Psicologia Escolar e Educacional, 19(3), 603-610.

Daniel, S. J. (2020). Education and the COVID-19 pandemic. Prospects, 49, 91-96.

Fernandes, M. A. et al. (2018). Prevalence of anxious and depressive symptoms in college students of a public institution. Revista Brasileira de Enfermagem, $71(5), 2169-2175$.

Lobo, A. P. (2020). Faltam PCs e acesso à Internet para massificar ensino a distância no Brasil. Associação Brasileira de Internet (ABRANEThttp://www.abranet.org.br/Noticias/Faltam-PCs-e-acesso-a-Internet-para-massificar-ensino-a-distancia-no-Brasil-

2940.html?UserActiveTemplate=site\&UserActiveTemplate=mobile\#.X4mZ_i_5SfW

Médici, M. S., Tathoo, E. R. \& Leão, M. F. (2020). Percepções de estudantes do Ensino Médio das redes pública e privada sobre atividades remotas ofertadas em tempos de pandemia do coronavírus. Revista Thema.

Moreira, E. \& Aragão, R. (2020). Ensino remoto: exclusão e precarização. Revista movimento. https://movimentorevista.com.br/2020/07/ensino-remotoexclusao-e-precarizacao/

Moreira, J. A., Henriques, S. \& Barros, D. (2020). Transitando de um ensino remoto emergencial para uma educação digital em rede, em tempos de pandemia. Dialogia, 34, 351-364.

Morin, E. (2003). Os sete saberes necessários à educação do futuro. Tradução de Catarina Eleonora F. da Silva \& Jeanne Sawaya; revisão técnica de Edgard de Assis Carvalho. 8. ed. São Paulo: Cortez, Brasília, DF: UNESCO.

Moura, A. A., Martins, E. D. \& Bernardo, A. de A. (2018). O processo de construção do conhecimento e os desafios do ensino-aprendizagem. Revista on line de Política e Gestão Educacional, 22(1), 410-423.

Oliveira, M. F. de. (2011). Metodologia científica: um manual para a realização de pesquisas em Administração. Catalão: UFG.

Prescott, R. (2020). Desigualdade no acesso à internet também se evidencia entre crianças e adolescentes. Associação Brasileira de Internet (ABRANET). http://www.abranet.org.br/Noticias/Desigualdade-no-acesso-a-internet-tambem-se-evidencia-entre-criancas-e-adolescentes-

2953.html ? UserActiveTemplate $=$ site $\% 2$ Cmobile $\% 252$ Csite $\% 252$ Cmobile $\% 2525252$ Csite $\% 2525252$ Cmobile $\&$ from $\% 255$ Finfo $\% 255$ Findex $=161 \&$ from $\% 5$ Fin fo $\% 5$ Findex=141\#.X4mb-i_5SfU

Gil, A. C. (2002). Como elaborar projetos de pesquisa. (4a ed.), Atlas.

Menezes, S. K. de O. \& Francisco, D. J. (2020). Educação em tempos de pandemia: aspectos afetivos e sociais no processo de ensino e aprendizagem. Revista Brasileira de Informática na Educação - RBIE, 28, 985-1012.

Monteiro, A. F., Alves, T. P., Laurino, D. P. Moura, A. C. de O. S. \& Vaniel, B. V. (2014). A afetividade na relação tutor-aluno: o ensinar e o aprender na educação online. In: Congresso Brasileiro de Ensino Superior a Distância.

Rego, T. C. (2014). Vygotsky: uma perspectiva histórico-cultural da educação. (25a ed.), Editora Vozes.

Santos, J. L. G. dos et al. (2017). Integração entre dados quantitativos e qualitativos em uma pesquisa de métodos mistos. Texto \& Contexto - Enfermagem [online], 26(3), 1-9.

Wallon, H. (2007). A evolução psicológica da criança. Martins Fontes.

Xiao, C. \& Li, Y. (2020). Analysis on the influence of epidemic on education in China. In: Das, V. \& Khan, N. (Org.). Covid-19 and Student Focused Concerns: Threats and Possibilities. American Ethnologist website, https://americanethnologist.org/features/collections/covid-19-and-student-focusedconcerns-threats-and-possibilities/analysis-on-the-influence-of-epidemic-on- education-in-china 